\title{
Protective properties of biotextile indicated by immature gamete cells flow cytometry and Drosophila melanogaster survival tests
}

\section{Dace Grauda*1, Andra Miḳelsone1, Dalius Butkauskas', 2, Dāvis Rašals, Inese Vilcāne ${ }^{1}$, Valters Gobiņšs ${ }^{1}$, Inga Lashenko3,4}

1 Institute of Biology, University of Latvia, Jelgavas Street 1, Riga, Latvia, LV-1004

2 Nature Research Centre, Akademijos Street 2, LT-08412, Vilnius, Lithuania

3 SIA “ILU Technologies”, Skārn,u Street, Riga, Latvia, LV-1050

4 Riga Technical University, Institute of Mechanics and Mechanical Engineering, Mechanics and Biotextile Research Laboratory, Kīpsalas iela 6B-406, Riga, Latvia, LV-1048

*Corresponding author: dace.grauda@lu.lv

\begin{abstract}
The testing of an innovative amber-containing biotextile developed within the EUREKA project IFSITEX revealed the ability of biotextile material to protect test objects from UV-B radiation and extremely low-frequency electromagnetic fields (ELF-EMFs). One of two different testing methods is based on flow cytometry indicating changes in the relative fluorescence of immature plant gametes based on the determination of the sum of changes in approximately 20 various parameters of gametic cells affected in one nuclear stage by irradiation of cell suspension covered with biotextile fabrics containing amber particles or similar fabrics lacking amber particles with UV-B for 75 minutes. The second test called Drosophila melanogaster survivability test, specifically modified for biotextile testing, revealed differences in the percentage of successful development of $D$. melanogaster from larvae to imago stage after growing fruit flies in tubes covered with biotextile material containing amber particles as well as material free of amber particles. Tubes with $D$. melanogaster larvae were placed in a Helmholtz coil were continuously exposed to a sinusoidal $50 \mathrm{~Hz}$ magnetic field (MF) at a flux of $450 \mu \mathrm{T}$. Survivability results were compared to the success of the development of the control which was not affected by experimentally generated ELF-EMFs $D$. melanogaster. Samples of biotextile containing amber particles were found to retain UV-B and LF-EMF radiation better than fabric samples without amber particles.
\end{abstract}

Keywords: Biotextile protection properties, UV-B, ELF-EMF, amber, immature gametic cells, Drosophila melanogaster 


\section{Introduction}

This paper reports the results from biotesting of biotextile's protective properties for shielding test objects from the impact of electromagnetic fields (EMF) and UV-B of different wavelengths. Test methods were selected and implemented so that they could be used to test the protective properties of new materials. During the development of new biotextile materials, close cooperation between textile engineers and biological testers has become commonplace, focusing on fast feedback as the results of bio-testing may significantly accelerate the development of new high-quality materials. Prior studies carried out at the University of Latvia (UL) and JLU Technologies Ltd showed that succinite possesses specific properties, i.e., the ability to increase parameters of cell activity, and it was emphasized that its influence on tested cells was harmless (Lyashenko, 2014; Grauda et al., 2015). It is known that amber (succinite) has characteristics (magnetic properties, ability to lose electrons as a result of impact of UV radiation, and content of polyether compounds) that potentially could decrease the influence of environmental factors such as increased UV-B radiation and experimentally low-frequency electromagnetic fields (ELF-EMFs). Thus, the current research was carried out to find the optimal concentration, as well as other parameters, of succinite particles used for the manufacturing of biotextile materials that would meet optimal mechanical and biological requirements. To determine the multivariate effects of newly developed biotextile materials on eukaryotic cells and model organisms, we choose to adapt relatively fast and reliable methods for applications in new areas like biotextile biotesting.

A complex approach to biotextile development led to positive changes in the development of new biotexstile materials: the development of laboratory tests used to determine biological activity of biotextiles and raw materials based on complex, systemic, and sustainable studies will have an essential impact on biotesting, making it more justified, comparable, repeatable, at the same time reducing costs.

\section{Materials and Methods}

The potential to use in vitro culture of gametic cells arranged for cultivation as described earlier (Barnabás, 2003; Kasha et al., 2003) was first demonstrated by our research group developing methods to study biotextile protective properties against UV-B and ELF-EMF ( $50 \mathrm{~Hz}$ magnetic field, $450 \mu \mathrm{T}$ ) radiation (Figure 1). We chose to study 8 considerable repeats using cyclamen (Cyclamen persicum) cells to perform testing based on flow cytometry (FCM) as one of the most rapid evaluations of changes of cell parameters after UV-B irradiation and for ELF-EMFs impact assessment. 
BD FACSJazz ${ }^{\circledast}$ cell sorter (BD Biosciences, USA) was used to test the relative fluorescence (RF) of cells. According to earlier tests performed using the blue laser (488 nm) (Grauda et al., 2015) new, original biotextile properties testing method was developed (the method is in the process of patenting). Statistical calculations were made using MS Excel software. The $p$-value threshold $(P<0.05)$ was used in evaluations of statistical significance.

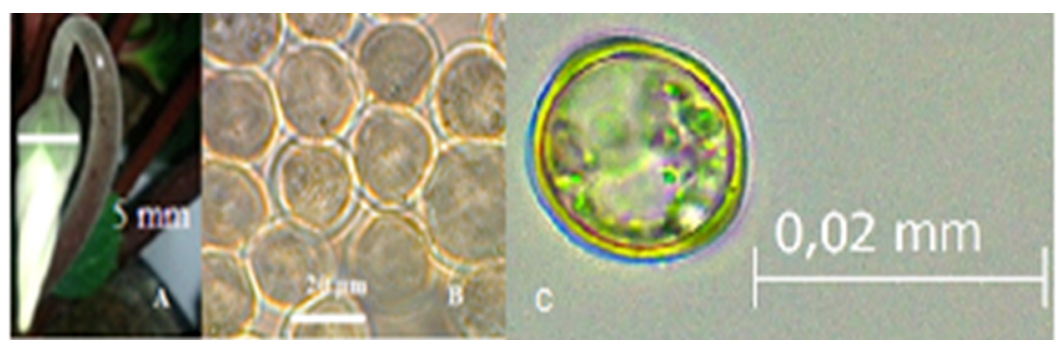

Figure 1. The buds of $C$. persicum (A) contain more than $80 \%$ gametic cells (microspores) in early and middle uninucleate developmental stage (B), Isolated gametic cell in the middle uninucleate developmental stage (C).

To determine the protective performance of different biotextile fabrics UV-B lamp was placed $30 \mathrm{~cm}$ above the table's surface (at $365 \mathrm{~nm}$ intensity). The Petri plates with the suspension of gametic cells were irradiated with UV-B keeping them in closed Petri dishes covered with different textile specimens made with incorporated and without incorporated amber yarn. Besides tested fabrics, a positive control (uncovered Petri dish) was used. The exposure to UV-B irradiation was continued for 70 minutes.

For determination of the anti- ELF-EMFs resistance of the newly formed textile materials, a Helmholtz coil was used (Figure 2). Specifically, the Helmholtz coil forms a constant magnetic field, $50 \mathrm{~Hz}$ inside of the device. The advantage of the Helmholtz coil for conducting experiments is that it produces a uniform magnetic flux generated by the magnetic field in the centre of the coil. The magnetic field intensity ranging from 0 to $725 \mu \mathrm{T}$ could be controlled by adjusting the electric current. Currently, $450 \mu \mathrm{T}$ and sinusoidal wave modulation was used to perform the experiments. Because this is a moderately high magnetic flux intensity, when compared with the existing EMFs exposure standards for electromagnetic fields, it may cause harm to human health increasingly depending on the time of exposure. 

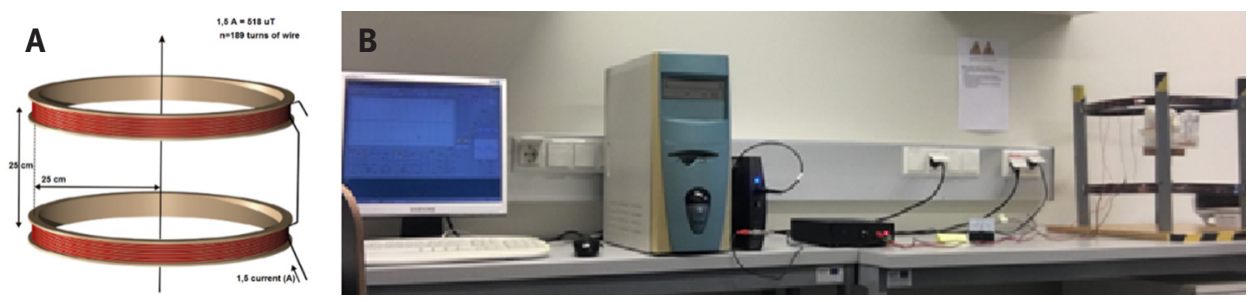

Figure 2. A. The Helmholtz coil, parameters: $R=25 \mathrm{~cm}$, Between the coils $=25 \mathrm{~cm}$, Turns of wire $=189, \mathrm{~B}$. The experimental system generates magnetic field intensity ranging from 0 to $725 \mu$ T could be controlled by adjusting the electric current.

To determine the protective performance of biotextile fabrics with the use of gametic cells the Petri plates with suspension in MS medium (Murasige and Skoog, 1962) of gametic cells were covered with textile specimens including the type of textile material made with incorporated amber yarn and similar material differing from the first type of material by the absence of incorporated amber yarn. Covered with materials of both types, Petri plates with the suspension of gametic cells were placed in the centre of the coil. Besides tested fabrics, a positive control (uncovered Petri dish) was used for comparison purposes. The exposure of gametic cells to $50 \mathrm{~Hz} 450 \mu \mathrm{T}$ irradiation was continued for $2 \mathrm{~h}$.

To study the protective performance of biotextile fabrics such as a classical test organism like D. melanogaster of the Origon laboratory line was used in so-called "Survival test" (Weisman et al., 2014) modified at the Environmental Genetics laboratory of the Institute of Biology, UL. The D. melanogaster larvae (length 1-2 mm) of line Origon were grown on Jazz-Mix food with concentration 18,9 g + $100 \mathrm{~mL}$ $\mathrm{H}_{2} \mathrm{O}$ planting larvae in tubes. Tubes with 30 larva's were covered with different textile specimens made with and without incorporated amber yarn, at least 2 repetitions of each variant were prepared and were placed in the center of the coil. Besides tested fabrics, a positive control (uncovered 2 tubes) was used. The exposure with $50 \mathrm{~Hz}$ magnetic field intensity of $450 \mu \mathrm{T}$ irradiation was continued for 2 generations of $D$. melanogaster. The rate of movement of imago was determined to reflect the overall physiological changes of flies. For the analysis, flies were put to sleep using a $\mathrm{CO}_{2}$ table, imago and dead larvae were counted in each stand and the proportion of male and female flies was determined.

\section{Results and Discussion}

Gametic cells from in vitro culture of $C$. persicum were chosen as a model system in this study because cyclamens were previously (Shabrangi et al., 2010; 
Grauda et al., 2015) found as sensitive to the influence of UV-B and their anthers contain plenty of good quality one nucleus stage gametic cells. Changes in RF in both samples incubated with UV-B and affected by ELF-EMF revealed enhanced protective properties of the tested fabrics when amber is woven into them. This is indicated by an increase in cellular relative fluorescence units (RFU) (brown peak) and a decrease of the fraction of apoptotic cells (blue peak) compared to controls represented by gamete cells incubated without tissue overlay (Figure 3).

The highest survival percentage was found in the group of larvae covered with textile that encompassed amber yarn. The survival of larvae that developed to imago in the group of $D$. melanogaster covered with textile without incorporated amber was lower. No larvae developed to the imago stage in both control (uncovered) groups treated with UV-B. Survival test of $D$. melanogaster demonstrates that the amber yarn increases the protective capacity of biotextile against UV-B irradiation enhancing the percentage of surviving larvae up to $20 \%$ (Figure 4).
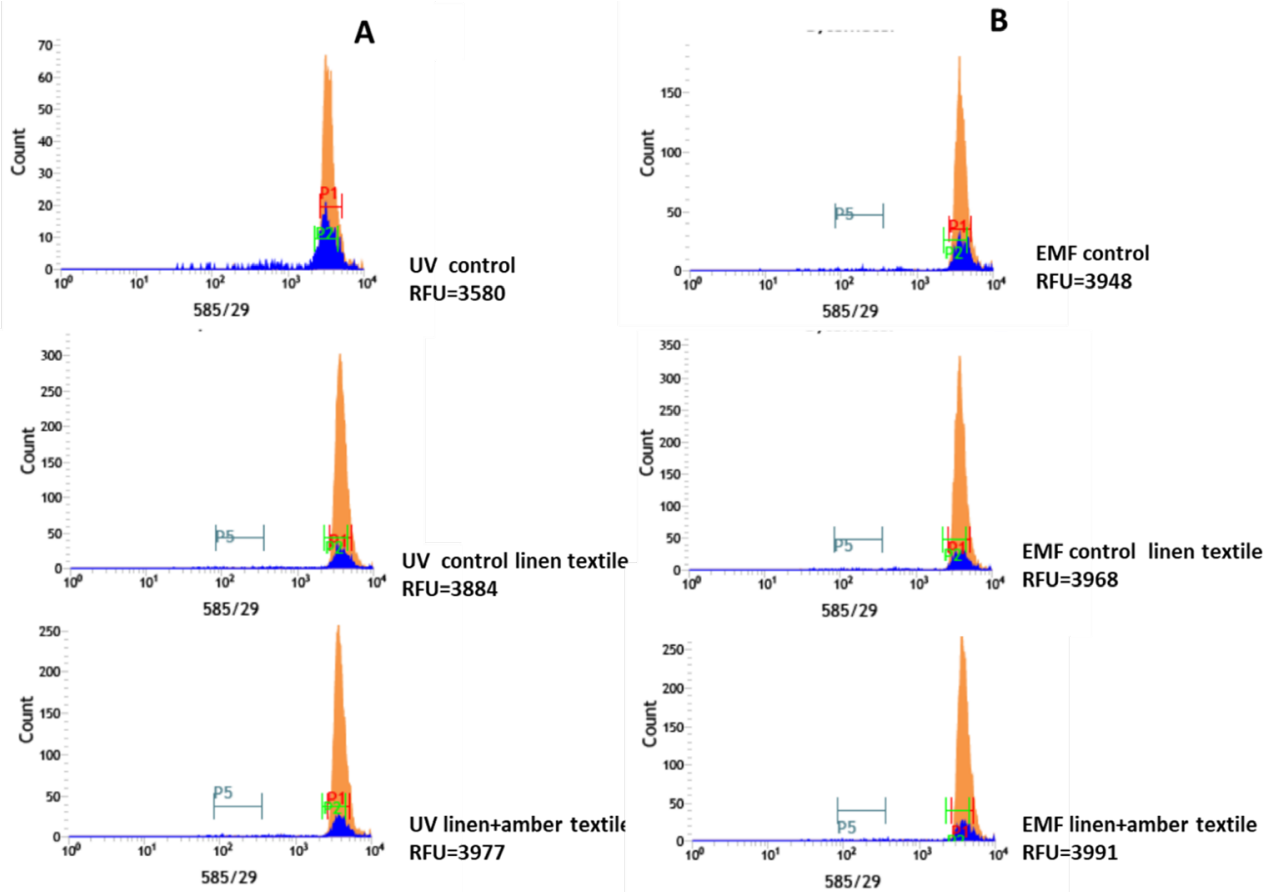

Figure 3. The changes of gametic cells RF depending on the type of fabric after incubation affected by UV-B (A) and impacted by ELF-EMF (B), brown peak shows fluorescence of viable cells, blue indicates apoptotic cell fluorescence. 


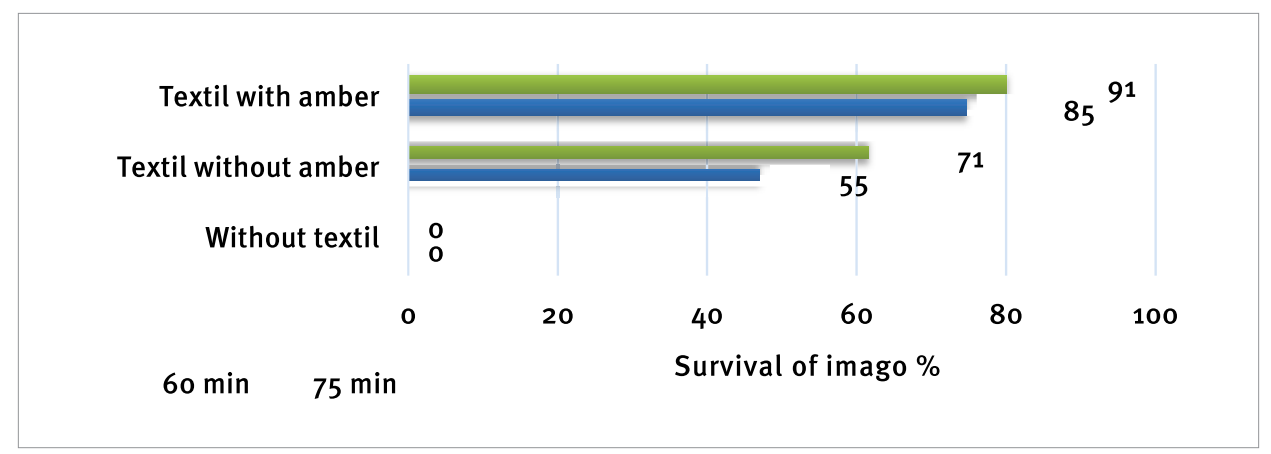

Figure 4. Survival of $D$. melanogaster imago depending on the duration (60 or $75 \mathrm{~min}$.) of UV-B treatment.

Linen textile containing amber micro particles was identified as a material that improved the survivability of $D$. melanogaster grown affected by ELF-EMFs ( $50 \mathrm{~Hz}$, magnetic field $450 \mu \mathrm{T}$ ) by up to $10 \%$, as the structure of cells didn't change in comparison to the absence of protective properties of other tested biotextile specimens (Figure 5).

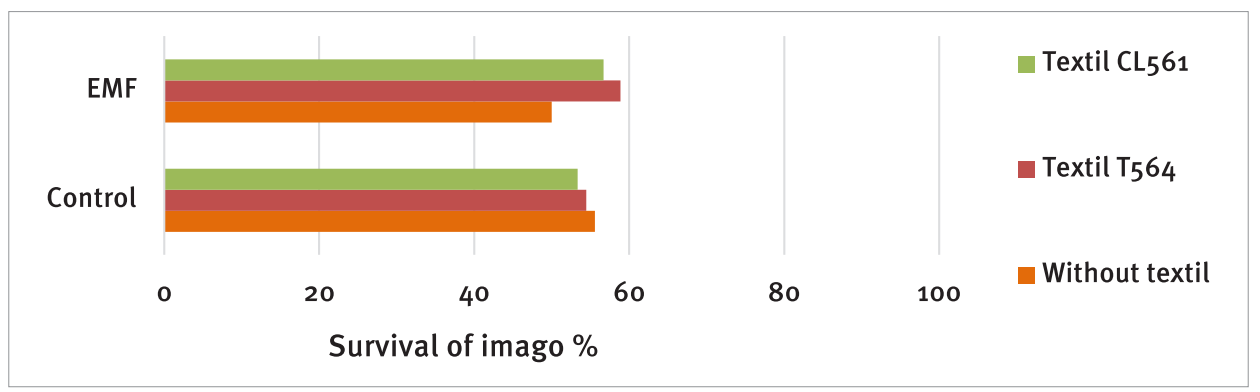

Figure 5. Survival of $D$. melanogaster imago after irradiation with ELF-EMF ( $50 \mathrm{~Hz}$ magnetic field), $450 \mu \mathrm{T}$ (“Textil CL561" - textile with amber; “Textil T564” - textile without amber).

Both bioassay methods presented in the current study were proved as suitable for testing the protective properties of biotextiles against UV and ELF-EMFs irradiation. It should be noted that FCM has several advantages, one being the large number of cells that can be evaluated in a very short time. When measuring changes of cell RF, it is possible to collect and analyse more than 20 parameters from each cell separately. The summarised changes of RFU generate statistically significant results representing the effect on a whole population of cells (Doležel et al., 2007; Dimpka et al., 2012). 
The plant cells have fluorescent pigments which depend on the species and cell specialisation they contain, fluorescent proteins in the chloroplasts, naturally fluorescent products such as proteins, including histones, and cell life process products (You et al., 2015). Fluorescence examination is considered as a standard for screening and diagnostic of early stages of the infection process in plants and changes in reinitiated cell culture; fluorescence would be an indicator of apoptotic cells (Vigneswaran et al., 2009; Martinez et al., 2010; Carter et al., 2013). On the other hand, UV-B irradiation and ELF-EMFs are well known as stress factors that could damage various cells processes. These damages can be classified into two categories - damage to DNA that can cause heritable mutations, and damage leading to disturbance of physiological processes. Certainly, detected increase of cell RF after UV-B irradiation and incubation in ELF-EMFs ( $50 \mathrm{~Hz}$ magnetic field, $450 \mu \mathrm{T}$ ) could be caused by changes in cell metabolism processes and peroxidase complex activity as a responsive reaction on stress factor (Karim et al., 2012; Peykarestan and Seify, 2012). All these factors together determine the cell self-fluorescence, and the method is sufficiently accurate and sensitive to be used to rapidly determine the protective properties of biotextiles.

D. melanogaster survivability test, which was modified for bio-textile testing, indicates the ratio between the number of successfully developed imago and those whose development was stopped. Obtained results show that bio-textile containing amber particles is more efficient at blocking the penetrance of UV-B rays and has a positive influence on the survival of D. melanogaster affected by ELF-EMFs in comparison to the group covered with textile not containing amber particles.

\section{Acknowledgements}

The study was financially supported by the EURECA project E!11170, IFSITEX.

\section{References}

Barnabás, B. 2003. Protocol for producing doubled haploid plants from anthers culture of wheat (Triticum aestivum L.). In: Doubled Haploid Production in Crop Plants. Eds. Maluszymski, Kasha, Forster and Szarejko. Pp. 65-70.

Carter, A. D., Bonyadi, R., and Gifford, M. L. 2013. The use of fluorescence-activated cell sorting in studying plant development and environmental responses. J. Dev. Biol. 57: 545-552.

Dimkpa, C. O., McLean, J. E., Latta, D. E., Manangó, E., Britt, D. W., Johnson, W. P., Boyanov, M. I., and Anderson, A. J. 2012. $\mathrm{CuO}$ and $\mathrm{ZnO}$ nanoparticles; phytotoxicity, metal speciation, and induction of oxidative stress in sand-grown wheat. J Nanopart Res. 14(9): 1-15.

Doležel, J., Greilhuber, J., and Suda, J. 2007. Flow cytometry with plants: an overview. In: Flow cytometry with plant cells. Eds. Doležel, Greilhuber, and Suda. Pp. 41-65. 
Grauda, D., Bumbure, L., Lyashenko, I., Katashev, A., Dekhtyar, Y., and Rashal, I. 2015. Amber particles as living plant cell markers in flow cytometry. Proceedings Latvian Academy Sci. Section B. 69(3): $77-81$.

Grauda, D., Kolodynski, A., Belogrudova, I., Bumbure, L., and Rashal, I. 2015. Combined effects of $50 \mathrm{~Hz}$ electromagnetic field and $\mathrm{SiO} 2$ nanoparticles on oxidative stress in plant's gametic cells. Proceedings Latvian Academy Sci. Section B. 69(3): 82-86.

Karim, Z., Adnan, R., and Ansari, M. S. 2012. Low concentration of silver nanoparticles not only enhances the activity of horseradish peroxidase but alter the structure also. PLoS ONE. 7(7), e41422.

Kasha, K. J., Simon, E., Oro, R., and Shim, Y. S. 2003. Barley isolated microspore culture protocol. In: Doubled Haploid Production in Crop Plants. Eds. Maluszynski, Kasha, Forster and Szarejko. Pp. 43-47.

Lyashenko, I. 2014. Assessment of the impact of amber solution on derma and subcutaneous tissue cell structure. In: Amber Way: Towards the Future of Latvia in the World. Ed. Knēts. Pp. 51-76.

Martinez, M. M., Reif, R. D., and Pappas, D. 2010. Early detection of apoptosis in living cells by fluorescence correlation spectroscopy. Anal. Bioanal. Chem. 396: 1177-1185.

Murashige, T., Skoog, F. 1962. A revised medium for rapid growth and bioassays with tobacco tissue cultures. Physiologia Plantarum. 15: 473-497.

Peykarestan, B., Seify, M. 2012. UV irradiation effects on seed germination and growth, protein content, peroxidaseand protease activity in red bean. International Research Journal of Applied and Basic Sciences. 3(1): 92-102.

Shabrangi, A., Majd, A., Sheidai, M., Nabyouni, M., and Dorranian, D. 2010. Comparing effects of extrremely low frequency electromagnetic fields on the biomass weight of $\mathrm{C} 3$ and $\mathrm{C} 4$ plants in early vegetative growth. Progress In Electromagnetics Research Symposiym Proceedings. Cambrige, USA, July 5-8, pp. 593-598.

Vigneswaran, N., Koh, S., and Gillenwater, A. 2009. Incidental detection of an occult oral malignancy with ultra-fluorescence imaging: A case report. Head Neck Oncol. 1(37). www. headandneckoncology.org/conten/1/1/37

Weisman, N. Y., Fedorov, V. I., and Nemova, E. F. 2014. Survival and life span of Drosophila melanogaster in response to terahertz radiation. Adv Geronto. 4: 87-192.

You, M. K., Lim, S.-H., Kim, M.-J., Jeong, Y. S., Lee, M.-G., and Ha, S.-H. 2015. Improvement of the fluorescence intensity during a flow cytometric analysis for rice protoplasts by localization of a green fluorescent protein into chloroplasts. Int. J. Mol. Sci. 16: 788-804. 